() 2016, Elsevier. Licensed under the Creative Commons Attribution-NonCommercial-NoDerivatives 4.0 International

http://creativecommons.org/licenses/by-nc-nd/4.0/

\title{
1 Pyrolysis and combustion of municipal solid wastes: Evaluation of synergistic effects using
}

2 TGA-MS

3 Sanjana D. Gunasee ${ }^{\mathrm{a}, \mathrm{c}^{*}}$, Marion Carrier ${ }^{\mathrm{b}, \mathrm{c}}$, Johann F. Gorgens $^{\mathrm{b}}$, Romeela Mohee ${ }^{\mathrm{d}}$

4

$5 \quad{ }^{a}$ Department of Chemical Engineering, University of Mauritius, Reduit, Mauritius

$6 \quad{ }^{\mathrm{b}}$ Department of Process Engineering, Stellenbosch University, South Africa

$7 \quad{ }^{c}$ Aston University, EBRI, Bioenergy Research group, Birmingham B4 7ET, United Kingdom

$8 \quad{ }^{\mathrm{d}}$ University of Mauritius, Reduit, Mauritius

9 * Corresponding author: Sanjana Gunasee; Email: san_gunasee@ hotmail.com; Tel:

$10+23057829952$

\section{Abstract}

15 A thermogravimetric methodology was developed to investigate and semi-quantify the extent of

16 synergistic effects during pyrolysis and combustion of municipal solid waste (MSW). Results

17 from TGA-MS were used to compare the pyrolysis and combustion characteristics of single

18 municipal solid waste components (polyvinyl chloride (PVC), polypropylene (PP), polystyrene

19 (PS), branches (BR), leaves (LV), grass (GR), packaging paper (PK), hygienic paper (HP) and

20 cardboard (CB)) and a mixture (MX) of PP, BR and CB. Samples were heated under dynamic

21 conditions at $20^{\circ} \mathrm{C} / \mathrm{min}$ from $25^{\circ} \mathrm{C}$ to $1000^{\circ} \mathrm{C}$ with the continuous record of their main evolved

22 fragments. Synergistic effects were evaluated by comparing experimental and calculated weight

23 losses and relative areas of MS peaks. Pyrolysis of the mixture happened in two stages, with the 
24 release of $\mathrm{H}_{2}, \mathrm{CH}_{4}, \mathrm{H}_{2} \mathrm{O} \mathrm{CO}$ and $\mathrm{CO}_{2}$ between $200-415^{\circ} \mathrm{C}$ and the release of $\mathrm{CH}_{4}, \mathrm{C}_{\mathrm{x}} \mathrm{H}_{4}, \mathrm{CO}$ and

$25 \mathrm{CO}_{2}$ between $415-525^{\circ} \mathrm{C}$. Negative synergistic effect in the $1^{\text {st }}$ stage was attributed to the

26 presence of $\mathrm{PP}$ where the release of hydrocarbons and $\mathrm{CO}_{2}$ from $\mathrm{BR}$ and $\mathrm{CB}$ was inhibited,

27 whereas positive synergistic effects were observed during the $2^{\text {nd }}$ degradation stage. In a second

28 part of the study, synergistic effects were related to the dependency of the effective activation

29 energy $\left(\mathrm{E}_{\alpha}\right)$ versus the conversion $(\alpha)$. Higher $\mathrm{E}_{\alpha} \mathrm{s}$ were obtained for MX during its $1^{\text {st }}$ stage of

30 pyrolysis and lower $\mathrm{E}_{\alpha} \mathrm{S}$ for the $2^{\text {nd }}$ stage when compared to the individual components. On the

31 other hand, mostly positive synergistic effects were observed during the combustion of the same

32 mixture, for which lower $\mathrm{E}_{\alpha} \mathrm{S}$ were recorded.

33 Keywords: Municipal solid wastes, TGA-MS, pyrolysis, combustion, synergy

\section{1. Introduction}

35 Rapid industrialization and population growth have led to an increase in generation of municipal

36 solid wastes (MSW) to such an extent that the management of solid wastes have become a major

37 concern in developing countries [1]. In Mauritius, solid wastes were traditionally disposed off in

38 open dumps and uncontrolled landfill, which pose potential environmental threats and health

39 issues [2]. At present, the waste generation rate per capita in Mauritius is higher than most

40 developing countries [3]. Two disposal methods namely landfill and composting are currently

41 applied, although the growth in solid waste generation and the lack of landfill space requires an

42 alternative solid waste treatment [4]. On the other hand, with Mauritius being highly dependent

43 on the import of petroleum to meet its requirement of energy, the government has proposed the

44 'Maurice Ile Durable' concept, aiming to be $65 \%$ self-sufficient in renewable energy by 2028 . As

45 such, thermochemical techniques can be applied for the treatment of MSW because they provide 
46 an efficient solution to reduce the volume of MSW, which can be subsequently converted into

47 recoverable energy as replacement for fossil fuels [5].

48 Combustion was suggested as an alternative to landfill and for the rejects of the non-compostable

49 fraction from the composting plant [4]. Combustion is the thermal processing of solid waste by

50 chemical oxidation with usually excess amount of air to produce a flue gas and a solid residue as

51 products [6]. The major combustible fractions of MSW in Mauritius are paper (12\% w/w),

52 plastic (13\%w/w) and yard waste (43\%w/w) [7]. Pyrolysis was also suggested as another

53 alternative for the treatment of MSW as it has received much attention during recent years.

54 Pyrolysis which is theoretically a zero-air indirect process for the thermal decomposition of

55 solids, presents the advantage of converting MSW into several usable products such as low

56 molecular weight gases, heavy volatiles (tar) and solid char [8,9]. The effect of heat on MSW

57 depends on the atmosphere used. The use of combustion or pyrolysis atmosphere causes different

58 types of reactions to happen and hence the degradation of solid wastes occurs by different

59 pathways producing different types of products.

60 Efficient conversion of solid wastes to energy products, through thermochemical techniques,

61 requires the understanding of their thermal behaviour [10]. Thermogravimetric analysis (TGA) is

62 a preferred technique to study the kinetic behaviour of samples' thermal degradation at low

63 heating rates although it provides limited information on products evolved and secondary

64 reactions of thermal conversion [11]. Coupling TGA with Fourier Transform Infrared

65 spectroscopy (FTIR) or with Mass Spectroscopy (MS) provides some information on the thermal

66 decomposition and reaction mechanisms. For example, Singh et al. [12] assessed the volatile

67 species evolved during the pyrolysis of several natural and synthetic polymers using both TGA- 
68 FTIR and TGA-MS techniques and concluded that both techniques were capable of providing

69 qualitative information on the volatile species evolved during pyrolysis.

70 Several researchers have applied TGA to study the pyrolytic $[5,8,13]$ and combustive $[14,15]$

71 characteristics of MSW, using selected individual waste components and/or mixtures. Previous

72 studies have shown that the pyrolysis and combustion degradation stages of various biomass

73 fuels and selected mixtures thereof were different $[10,16]$. Under inert atmosphere, each

74 material degraded in a single stage, depending on the content and composition of inorganics,

75 while between two and three degradation stages were observed for each component under

76 combustion conditions. In addition, thermal decomposition processes occur at lower

77 temperatures in oxidising atmospheres as compared to pyrolysis conditions. However, there are

78 few comparative studies on the volatiles evolved from the components of MSW during

79 combustion and pyrolysis $[12,17,18]$.

$80 \mathrm{MSW}$ is a complex mixture of different types of components. During pyrolysis and combustion

81 of MSW, the different components do not degrade independently in the mixture and some

82 interactions may give rise to synergies. Synergy occurring during co-pyrolysis and co-

83 combustion is the difference between the actual experimental yield or composition of the

84 products and the value calculated according to the ratio of the individual components in the

85 mixture [19]. Several researchers mentioned that the mechanism of synergistic effect between

86 plastic and biomass is still unclear [20,21]. Besides, while many works describe the thermal

87 behaviour of single feedstocks, few have attempted to describe the apparent activation energy of

88 potential reactional synergies occurring during the thermal conversion of a mixture [22].

89 Therefore, the aim of this work is to study both pyrolysis and combustion of typical municipal

90 wastes to gain knowledge on eventual synergistic mechanisms. To do this, we used the TGA-MS 
91 technique and determine activation energies to quantitatively describe the extent of synergetic

92 mechanisms and associated threshold..

93 2. Materials and methods

$94 \quad 2.1$ Materials

95 Combustible fractions from municipal solid wastes (MSW) were selected as feedstocks. In total,

96 nine different feedstocks were classified in three main categories: plastics [polyvinyl chloride

97 (PVC), polypropylene (PP), polystyrene (PS)], paper wastes [cardboard (CB), hygienic paper

98 (HP), packaging paper (PK)], and yard wastes [pine wood branches (BR), leaves (LV) and grass

99 (GR)]. A mixture (MX) between polypropylene, cardboard and branches at a mass ratio 1:1:1

100 was also prepared. Feedstocks were cut down into small pieces using a Rockwell mill and a

101 chipper for PVC and branches and milled to a $2 \mathrm{~mm}$ particle size using a cryogenic grinder

102 (Retsch SM 100).

103 A representative sample of each material was obtained using the standard method of coning and

104 quartering (SABS method). The particle size distribution was determined using a Retsch sieve

105 shaker operating for 10 minutes. Samples of particle size between $250 \mu \mathrm{m}$ and $1 \mathrm{~mm}$ were used

106 in the TGA experiments.

$107 \quad 2.2$ Analyses

108 Proximate analysis of feedstocks was carried out in accordance to the ASTM E1131 by means of

109 a Mettler Toledo TGA/DSC1 thermogravimetric analyser. Samples were loaded in $900 \mu \mathrm{L}$

110 alumina crucibles and were heated under a $\mathrm{N}_{2}$ (99.999\% Baseline 5.0, Afrox) flow of $80 \mathrm{~mL} / \mathrm{min}$

111 at a heating rate of $50^{\circ} \mathrm{C} / \mathrm{min}$ from $30^{\circ} \mathrm{C}$ to $110^{\circ} \mathrm{C}$, following which an isothermal region was

112 maintained for $30 \mathrm{~s}$. The heating rate was then increased to $100^{\circ} \mathrm{C} / \mathrm{min}$ until a temperature of 
$113900^{\circ} \mathrm{C}$ was reached after which a second isothermal region was hold for 5 minutes. Finally, the

114 atmosphere was changed from $\mathrm{N}_{2}$ to $\mathrm{O}_{2}(99.998 \%$ Baseline 4.8 , Afrox), which flow rate was 80

$115 \mathrm{~mL} / \mathrm{min}$ for a further 5 minutes, to allow for complete combustion and determination of the ash

116 content.

117 Ultimate analysis was carried out using a LECO TruSpec Micro Elemental Analyser where the

118 amount of elemental carbon, hydrogen, nitrogen and sulphur present in each component was

119 determined. The oxygen was calculated by difference. The higher heating value (HHV) of the

120 feedstock was determined by means of an Eco cal2K bomb calorimeter. However, no calorific

121 value could be obtained for PVC as the release of large amount of hydrochloric acid during its

122 combustion is potentially corrosive. The results are presented in Table 1.

124 The thermal decomposition of individual components in MSW and their mixture was carried out 125 in a Mettler Toledo TGA/DSC 1 analyser. Each sample $(10-20 \mathrm{mg})$ was placed in a $70 \mu \mathrm{L}$ 126 alumina crucible and placed into the furnace where it was heated from $25^{\circ} \mathrm{C}$ to $1000^{\circ} \mathrm{C}$ at heating 127 rate $20^{\circ} \mathrm{C} / \mathrm{min}$. The mass used varied between the samples since their densities were different. 128 Low sample masses and low heating rate were chosen so as to reduce the occurrence of 129 secondary vapour solid interactions and the effect of mass and heat transfer [23]. Blank runs 130 were carried out to determine the effect of buoyancy on the experiments following which the 131 TGA curves were corrected. Pyrolysis and combustion experiments were carried out using 132 Argon (99.999\% baseline 5.0, Afrox) and air $\left(21 \% \mathrm{O}_{2} / 79 \% \mathrm{~N}_{2}\right.$, Afrox $)$ respectively, at a flow rate $13350 \mathrm{~mL} / \mathrm{min}$, with a hold time of 5 minutes before the start of the reaction, to ensure identical 134 temperature distributions and thermal equilibrium of the samples at the start of the experiments. 135 Weight loss measurements of the samples were recorded every 0.7 seconds. TGA experiments 
136 were carried out in duplicate to confirm the reproducibility of the results. Data obtained from the

137 TGA were interpreted and manipulated using the STARe-Evaluation software version 13.0

138 supplied by AKTS.

139 Volatile products were analysed by a mass spectrometry (MS) coupled to the TGA. A

140 representative portion of the evolved gas components from the TG analyser was fed to a Pfeiffer

141 Vacuum Thermostar GSD320 Gas Analysis System mass spectrometer through a well insulated

$1425 \mathrm{~m} \times 150 \mu \mathrm{m}$ fused silica capillary heated to $200^{\circ} \mathrm{C}$. The input gas was ionised by a bombardment

143 of electrons under positive electron impact ionization energy of $70 \mathrm{eV}$. Cations were separated by

144 a quadruple mass filter and reached a SEM MS detector. The subsequent mass spectrum provides

145 a fingerprint of the complex vapours. Preliminary sensitivity and linearity tests using $\mathrm{CaCO}_{3}$

146 standard were carried out to avoid any saturation of the detector and confirming the position of

147 the capillary at the furnace exit.

148 In order to select the relevant molecular ions to track during the degradation, a preliminary-MS

149 scan of the overall volatiles was applied to screen all ionic species in the range of 1 to $300 \mathrm{amu}$

150 emitted by each sample recorded over 42 cycles. After comparison of the scans with literature

$151[12,18,24]$ a list of 8 common fragments of the most intense (I > $\left.10^{-12} \mathrm{~A}\right)$ fragments

152 (Supplementary data S1) were chosen. The intensity of the signal was normalised to the sample

153 size and to the carrier gas ion $(\mathrm{m} / \mathrm{z} 40)$ in order to have a comparable ion current across different

154 stages and between different samples and to eliminate systematic instrumental errors.

155 The sensitivity and linearity of the MS detector was checked by pyrolyzing four different sample

156 weights of $\mathrm{PVC}(5,10,15$ and $20 \mathrm{mg})$ under dynamic regime at $20^{\circ} \mathrm{C} / \mathrm{min}$ with a flow of 50

$157 \mathrm{~mL} / \mathrm{min}$ of Argon (99.999\% baseline 5.0, Afrox). The plot of ion peak areas versus the initial

158 masses of PVC introduced (Supplementary data S2) displayed a linear trend $\left(\mathrm{R}^{2}=0.9884\right)$ 
159 indicating that the MS was sensitive enough with low sample masses and that a direct

160 relationship between the peak area and the sample mass could be used.

161 The effective activation energy as a function of conversion was evaluated for the samples and

162 mixture using the popular isoconversional analysis, Friedman's method. The samples were

163 heated from 25 to $1000^{\circ} \mathrm{C}$ using four heating rates $\left(10,20,30\right.$ and $\left.50^{\circ} \mathrm{C} / \mathrm{min}\right)$ under both

164 pyrolysis and combustion conditions as described above. Although these heating rates appear to

165 be too high according ICTAC kinetics committee recommendations [25] to insure the kinetic

166 regime, the main objective of this study was to demonstrate that the TGA-MS method is an

167 adequate technique to semi-quantify synergistic events during the devolatilization of complex

168 polymers by combining devolatilization rates $(\mathrm{d} \alpha / \mathrm{dt})$ and relative areas of MS peaks. All

169 resulting weight loss using TGA and their corresponding rate obtained from DTG curves at

170 different temperatures were treated using the Advanced Thermal Kinetics Software (AKTS

171 version 3.18). The $\mathrm{E}_{\alpha}$-dependency curves versus the extent of conversion were obtained using the

172 Friedman's method as described in detail by Aboyade et al. [26]. The equation used for the

173 determination of the apparent activation energy is given as:

$$
\ln (\beta(d \alpha / d t))=\ln [A . f(\propto)]-E / R T
$$

175 Where $\alpha$ is the conversion fraction, $\beta$ is the heating rate, $f(\alpha)$ is the reaction model, $A$ is the

176 Arrhenius pre-exponential factor and $E$ the activation energy. A plot of $\ln (\beta(\mathrm{d} \alpha / \mathrm{dt}))$ against $1 / \mathrm{T}$

177 for values obtained for different heating rates $(\beta)$ at the same conversion $(\alpha)$ results in lines. The

$178 \mathrm{E}_{\alpha}$-dependency analysis has been proven to be a powerful tool to describe key features of thermal 179 conversions [27].

180 3. Results and Discussion

1813.1 Weight loss profiles of MSW during pyrolysis and combustion 
183 Each material was exposed to inert and oxidative thermal treatments and the main degradation 184 stages are illustrated in Figures 1 and 2. Tables 2 and 3 summarise the main characteristics of 185 TGA and DTG curves such as the temperature range in which the degradation took place, the 186 temperature at which the maximal rate of loss weight occurred and the final percentage of solid 187 residue. All materials except PVC and PK were pyrolysed in one stage (Figure 1). The pyrolysis 188 degradation of PVC occurred in two distinct steps with peaks observed at $309^{\circ} \mathrm{C}$ and $450^{\circ} \mathrm{C}$ on 189 the DTG curve which are in line with previous research on the pyrolytic behaviour of PVC [28].

190 The other two plastics PP and PS decomposed in a narrow range of temperature (Figure 1 and 191 Table 2). Both plastics containing a high VM content (Table 1) presented similar pyrolysis trends 192 with the fastest rates of weight loss (Table 2). This single stage degradation can be explained by 193 the very homogeneous structure of plastics as mentioned by Bockhorn et al. [29]; with PP and 194 PS's degradation occurring through the same radical chain mechanism, initiating via random 195 scission followed by radical transfer. Hence the difference in the TG curves of PVC and the 196 other two plastics can be attributed to the different macromolecular structure and pyrolysis 197 mechanisms. The remaining solid residue for plastics (Table 2), as indicated by the presence of 198 ash content (Table 1) is mainly due to the presence of additives, with fibre glass being the most 199 common [30].

200 In the case of yard and paper wastes, the weight loss occurring below $100{ }^{\circ} \mathrm{C}$ is attributed to the 201 loss of moisture [31]. Subsequent to dehydration, the degradation of the components in

202 lignocelluloses (BR, LV, GR) with the lowest thermal stability started at the lowest temperatures, 203 which corresponded to the typical degradation temperature range of hemicelluloses $\left(160-360^{\circ} \mathrm{C}\right)$ 204 [32]. Cellulosic-based (CB, HP) wastes started to degrade at a slightly higher temperature (210- 
$230^{\circ} \mathrm{C}$ ), which corresponded to the reported temperature range of cellulose degradation (i.e., 240-

$206390^{\circ} \mathrm{C}$ ) [32]. The lignocellulosic-based (BR, LV, GR) materials presented broader degradation

207 range (Figure 1) which was characteristic of the decomposition of lignin reported over a wide

208 temperature range $\left(180-900^{\circ} \mathrm{C}\right)[32]$ and to their higher FC content (Table 1). Brebu and Vasile

209 [33], further attributed the broad temperature range for the thermal degradation of lignin to

210 differences in thermal stabilities of the various oxygenated functional groups present in lignin. A

211 change in the slope above $500^{\circ} \mathrm{C}$ for the lignocellulosic-based (BR, LV, GR) materials shows a

212 slower rate of weight loss (Table 2), corresponding to a combination of the end of cellulose

213 degradation and the start of secondary degradation of heavier volatiles and char formation

214 process [31]. The latter restricts the mass transport at the solid/gas interface and hence slows

215 down the rate of escape of the volatized gases [31]. On the other hand, PK paper's degradation

216 pathway differed from the other cellulosic-based materials with two distinct peaks observed on

217 the DTG curve at $362^{\circ} \mathrm{C}$ and $486^{\circ} \mathrm{C}$, respectively. A small shoulder peak was also observed at

$218690^{\circ} \mathrm{C}$. Similarly to HP and CB, the first stage of degradation between $250^{\circ} \mathrm{C}$ and $400^{\circ} \mathrm{C}$

219 corresponded to the degradation of cellulose. Skreiberg et al. [10] reported that the second stage

$220\left(400-510^{\circ} \mathrm{C}\right)$ was a result of the degradation of $\mathrm{CaCO}_{3}$ to $\mathrm{CaO}$ and $\mathrm{CO}_{2}$. Calcium carbonate is

221 often used as additives in these types of paper. A further thermal degradation above $500^{\circ} \mathrm{C}$

222 indicated the existence of more stable molecules or intermediates, inert below this temperature.

223 Analyzing the width of the temperature range in which pyrolysis takes place for the different

224 samples, it can be seen that the 9 MSW components can be put into the following order: PS, PP,

225 BR, LV, PVC, HP, CB, GR and finally PK. PP, PS and BR had completed their thermal

226 degradation by $500^{\circ} \mathrm{C}$. The first three components are also the materials with the lowest ash

227 content (Table 1). PK and GR, containing the highest ash content, continued to lose weight 
228 above $600^{\circ} \mathrm{C}$ and were the most difficult to break down. The lower DTG peak observed for 229 grasses was also reported in other studies [13] and was explained by the higher ash content of

230 GR (Table 1) and the difference in the composition of ash.

231 The TGA and DTG curves of the combustion of the different components are presented in Figure

232 2. The DTG curves for all lignocellulosic-based materials (BR, LV, GR) were practically

233 identical (Figure 2). The first degradation stage was in the range of $200-380^{\circ} \mathrm{C}$ and could be

234 attributed to the breakdown of hemicelluloses and cellulose [32] up to $300^{\circ} \mathrm{C}$. The second

235 combustion-degradation stage $\left(370-550^{\circ} \mathrm{C}\right)$, which was not clearly observed during pyrolysis,

236 corresponded to the degradation of lignin although most probably due to the oxidation of char

237 [34]. In most cases, the combustion of the feedstocks occurred at lower temperatures than

238 pyrolysis (Table 3 and Supplementary data S3 for direct comparison of DTG curves). In

239 particular for the lignocellulosic-based (BR and LV) and cellulosic based (CB, HP, PK)

240 feedstocks, the rate of combustion (Table 3) was faster than the rate of pyrolysis (Table 2) at one

241 exception for the grass, which displayed the lowest $\mathrm{O}$ content but also the highest ash content

242 (Table 1). An increase in the content of oxygen and fixed carbon was thus beneficial to the rate

243 of combustion. These oxidation conditions also facilitated the devolatilization of inorganics for

244 all of the individual components considered, resulting in a lower weight fraction of residual

245 solids after processing (Table 3). Furthermore, the combustion of lignocellulosic-based materials

246 presents more stages of degradation than their pyrolysis degradation (Supplementary data S3).

247 Similarly to pyrolysis, the combustion of plastic materials, PP and PS, occurred in a single stage

248 but at lower temperatures $\left(260-425^{\circ} \mathrm{C}\right)$. The absence of the second combustion stage indicated

249 that no char was formed during the first stage of combustion, since these two plastics had a high

250 VM content (Table 1). In the case of the combustion of PVC, a three staged degradation was 
251 observed indicating the formation of char and its combustion in the last stage at high temperature

252 of $610^{\circ} \mathrm{C}$ (Figure 2). Once again, the cellulosic-based material PK presented three-stage

253 degradation under oxidative atmosphere. After a first volatilization at $335^{\circ} \mathrm{C}$ and the combined

254 combustion of lignin and char $\left(425^{\circ} \mathrm{C}\right)$, a third stage at $672^{\circ} \mathrm{C}$ was observed and could be

255 attributed to the decomposition of calcium carbonate to calcium oxide and carbon dioxide [10].

$256 \quad 3.1 .2$ For the mixture

257 The mixture consisted of one material from each feedstock group (i.e., lignocellulosic, cellulosic 258 and plastic-based materials), PP, CB and BR. This preparation was subjected to pyrolysis and 259 combustion under $20^{\circ} \mathrm{C} / \mathrm{min}$ and main results are summarized in Figure 3. Under pyrolysis, the 260 mixture was devolatilized in two distinct stages centred at 375 and $481^{\circ} \mathrm{C}$ (Table 2), with the 261 former peak attributed to both devolatilization of hemicelluloses and cellulose fractions from

262 lignocellulosic and cellulosic-based materials, while the latter mainly to PP devolatilization with 263 minor contributions of lignin degradation, present in CB and BR (Table 2). Similar observations 264 were made during the thermal degradation of MSW under inert conditions, which were attributed 265 to the successive contributions of primary decomposition and secondary reactions [35].

266 Two stages of decomposition were detected during combustion (Figure 3) of the mixture. The 267 two combustion stages overlapped to a greater extent when compared to the DTG curve of 268 pyrolysis. Larger extents of volatile release, occurring at lower temperatures, were observed for 269 combustion of the mixture, compared to pyrolysis (Tables 2 and 3), as was also observed with 270 combustion/pyrolysis of single components. Significant weight loss of $88 \%$ was observed during 271 the first combustion stage $\left(225-400^{\circ} \mathrm{C}\right)$, associated with the decomposition of all the three 272 components in the mixture (Table 3$)$. A relatively weak and narrow peak $\left(425^{\circ} \mathrm{C}\right)$ was observed 273 in the second stage corresponding mostly to the oxidation of char and slow degradation of lignin. 
274 The rate of devolatilization for the first peak was higher during combustion while the second 275 peak was higher during pyrolysis.

\subsubsection{Analysis of synergistic interactions during MSW mixture pyrolysis and combustion}

277 The degradation of lignocellulosic-based and plastic materials occur through different types of

278 mechanisms which can give rise to synergies. Usually lignocellulosic-based materials degrade

279 through a series of different endothermic and exothermic reactions involving ionic/non-ionic

280 reactions [36] while plastic degradation has been reported to occur through radical mechanism.

281 In order to investigate the synergistic behaviour between the lignocellulosic-based and plastic

282 materials in the mixture, theoretical DTG curves were also calculated as the sum of the weight

283 loss rate contributions from BR, CB and PP fractions obtained under same conditions as shown

284 in Figure 4. It was then assumed that there is no interaction between the different materials

285 within the mixture. The predicted DTG curve was obtained using an additive equation (2):

$$
Y=\left(x_{c} Y_{c}+x_{b} Y_{b}+x_{p} Y_{p}\right) / 100
$$

287 where $\mathrm{Y}$ refers to the predicted weight loss rate for the blended sample, $\mathrm{Y}_{\mathrm{b}}$ is the observed 288 weight loss rate at $100 \% \mathrm{BR}, \mathrm{x}_{\mathrm{b}}$ is the fraction (\%) of $\mathrm{BR}$ in the blend sample, $\mathrm{Y}_{\mathrm{c}}$ is the observed 289 weight loss rate at $100 \% \mathrm{CB}, \mathrm{x}_{\mathrm{c}}$ is the fraction (\%) of CB in the blend sample, $\mathrm{Y}_{\mathrm{p}}$ is the observed 290 weight loss rate at $100 \% \mathrm{PP}$ and $\mathrm{x}_{\mathrm{p}}$ is the fraction (\%) of PP in the blend sample.

291 Under pyrolytic conditions, from the first peak at $375^{\circ} \mathrm{C}$, the reaction is slower than the

292 calculated results showing some interactions between BR and CB, which is known to decompose

293 in this temperature range. A slight shift of the second peak to higher temperatures could be

294 observed. Synergistic effects were more evident for combustion of MX. The two expected peaks

295 at $340^{\circ} \mathrm{C}$ (BR and $\mathrm{CB}$ ) and $380^{\circ} \mathrm{C}(\mathrm{PP})$ have merged to produce one single peak at $348^{\circ} \mathrm{C}$. The 
synergistic behaviour for the mixture under combustion conditions occurred over the temperature

297 range from $260^{\circ} \mathrm{C}$ to $515^{\circ} \mathrm{C}$.

298 To further discuss on the extent of the synergistic effect during the pyrolysis and combustion of

299 the mixture, the difference of weight loss, $\Delta \mathrm{W}(\%)$, was calculated using equation (3).

$$
\Delta W=W_{\text {mix }}-\left(x_{b} W_{b}+x_{c} W_{c}+x_{p} W_{p}\right)
$$

301 Where $\mathrm{W}_{\text {mix }}$ is the experimental value from the TG curve of the mixture and $\mathrm{W}_{\mathrm{b}}, \mathrm{W}_{\mathrm{c}}$ and $\mathrm{W}_{\mathrm{p}}$ are

302 the weight losses from the TG curves of $100 \%$ BR, CB and PP. Figure 5 shows the plots of the

303 synergistic effects for the pyrolysis and combustion of MX. Negative values show a synergistic

304 effect towards the formation of char while positive values indicate synergistic effect during co-

305 pyrolysis and co-combustion for the formation of volatiles. For pyrolytic degradation, in the

306 temperature range of $25-330^{\circ} \mathrm{C}$, a positive deviation of around $1.5 \%$ was observed indicating that

307 a minimum interaction between CB and BR occurred with a slightly higher release of volatiles

308 than expected. Between $330-500^{\circ} \mathrm{C}$, two peaks can be observed on the curve that can be related

309 to negative synergistic effects. The first peak at $400^{\circ} \mathrm{C}$, corresponding to the beginning of the

310 thermal degradation of PP, indicated that reactions between pyrolysis intermediates evolved from

311 the decomposition of the mixture led to the formation of more thermally stable compounds than

312 in the case of the single feedstock. At this temperature, the main degradation zone for PP, BR

313 and CB overlaps. The presence of intermediate species evolved during the degradation of BR

314 and CB could affects the degradation of PP by abstracting free hydrogen produced during

315 pyrolysis (Hydrogen transfer effect). Therefore the first negative synergistic peak observed is

316 most probably due to the abstraction of hydrogen by reactive species (e.g., radicals) which are

317 not available anymore to participate further in depolymerisation reactions. The second peak, with

318 a maximum of $-4 \%$ at $480^{\circ} \mathrm{C}$ is coincident with the DTG peak temperature of degradation of PP 
(Table 2). The volatile matter content of PP (Table 1) is much greater than that of BR and CB. At

320 this temperature $\left(480^{\circ} \mathrm{C}\right)$, during the degradation of MX, a large quantity and wide variety of

321 volatiles was released from PP in a very short time period (Figure 6). Some of the volatiles may

322 have been trapped in the particles' voids or condensed on BR, CB and PP particles' surface

323 preventing the volatiles to be released. Further increase in temperature $\left(>500^{\circ} \mathrm{C}\right)$ resulting in an

324 inner pressure of the particles of BR, CB and PP was then beneficial for the formation and

325 release of volatiles. Also, the negative synergistic effect due to the abstraction of hydrogens

326 reported earlier at lower temperature is reduced since the degradation of PP should be completed

327 by $500^{\circ} \mathrm{C}$ (Table 2). Positive deviation of around $3 \%$ was therefore observed and consistent over

328 the whole conversion suggesting that interactions between reactive volatiles and/or between

329 volatiles/solid promoted devolatilization reactions or inhibited reactions such as re-condensation

330 and char formation. Past work on co-pyrolysis of plastic and biomass suggested that the

331 formation of reactive radicals from PP could have catalyzed the decomposition of lignin

332 producing more volatiles than expected towards the end of the degradation [37]. To further

333 analyse the extent of synergistic effect, the root mean square (RMS) value was used. This

334 method used in previous research allows the determination of the error between the measured

335 and predicted values [22]. The RMS value of the deviation between the measured and calculated

336 value was 2.38 which suggest that there were indeed synergistic effects during the co-pyrolysis

337 of $\mathrm{BR}, \mathrm{CB}$ and $\mathrm{PP}$ resulting in an overall less residual char.

338 During combustion, no difference in weight loss was observed $(\Delta \mathrm{W}<0.6 \%)$ below $250^{\circ} \mathrm{C}$. In the

339 temperature range of $260-500^{\circ} \mathrm{C}$, large and positive deviations in weight loss was obtained with

340 two peaks occurring at 340 and $370^{\circ} \mathrm{C}$. The first synergistic peak with a maximum of $9.2 \%$, was

341 coincident to the peak DTG for both degradations of BR and CB (Table 3) and the early stage of 
342 PP degradation, which indicates that significant synergistic mechanisms promoting the

343 devolatilization of solid occurred. Contrary to pyrolysis, the formation of free hydrogen radicals

344 from PP is significantly reduced in the presence of oxygen. Therefore positive deviations

345 observed could be related to the formation of steam, which could promote the further cracking of

346 char from BR and CB leading to the formation of more volatiles. The second peak with a

347 maximum of $14 \%$, occurred at the critical temperature where PP degraded (Table 3 ) together

348 with the second stage of degradation of individual lignocellulosic components, BR and CB.

349 Radicals formed during the degradation of PP contributed to the formation of volatiles from BR

350 and $\mathrm{CB}$; thus suggesting that the nature of volatiles produced under oxidative atmosphere is more

351 reactive. Above $500^{\circ} \mathrm{C}$, negligible and positive deviations $(\Delta \mathrm{W}<1 \%)$ were depicted (Figure 5). A

352 RMS value of 3.37 for the $\Delta \mathrm{W}$ was obtained which was higher than that obtained during

353 pyrolysis. The RMS values indicated that the consequences related to the synergistic effects

354 during the co-thermal conversion of BR, CB and PP yielded to smaller solid residue.

\subsection{Evolved gas analysis during MSW pyrolysis and combustion}

\subsubsection{For individual materials - common fragments}

357 The composition of gaseous products from the pyrolysis and combustion of individual

358 components were analysed by online MS coupled to TGA. Figures 6 and 7 show the evolution of

359 the six common fragments under pyrolytic and combustive conditions respectively. The

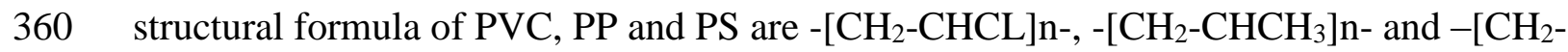

$\left.361 \mathrm{CHC}_{6} \mathrm{H}_{6}\right] \mathrm{n}$ - respectively. Since no oxygen is present in the structure of these materials, in theory

362 it suggests that $\mathrm{H}_{2} \mathrm{O}, \mathrm{CO}$ and $\mathrm{CO}_{2}$ should be absent in gaseous products obtained from their

363 pyrolysis. Hence, the evolution profiles of $\mathrm{H}_{2} \mathrm{O}, \mathrm{CO}$ and $\mathrm{CO}_{2}$ for $\mathrm{PVC}, \mathrm{PP}$ and PS were not

364 considered in Figure 6(a, b and c). When comparing the relative abundance of some selected 
365 molecular ions (i.e. $\mathrm{H}_{2}, \mathrm{CH}_{4}, \mathrm{H}_{2} \mathrm{O}, \mathrm{C}_{\mathrm{x}} \mathrm{H}_{\mathrm{y}}, \mathrm{CO}$ and $\mathrm{CO}_{2}$ ) common to all feedstocks, $\mathrm{H}_{2}, \mathrm{CH}_{4}$ and

366 other hydrocarbons (HCs) were found to be released more abundantly under pyrolysis

367 conditions, while $\mathrm{H}_{2} \mathrm{O}, \mathrm{CO}$ and $\mathrm{CO}_{2}$ presented the highest intensities during combustion.

$368 \mathrm{H}_{2} \mathrm{O}$ in gaseous products

$369 \mathrm{H}_{2} \mathrm{O}$ release characterized by molecular ion fragment $18 \mathrm{amu}$, was released at several stages

370 during the pyrolysis of natural polymers. Figures $6 \mathrm{~d}-\mathrm{h}$ revealed the presence of two peaks for

$371 \mathrm{H}_{2} \mathrm{O}$ during the thermal degradation of yard and paper wastes. The first peak below $200^{\circ} \mathrm{C}$ can be

372 related to the first peak observed on the DTG curves of ligno-cellulosic based materials (Figure

373 1b) which corresponded to the release of moisture. The second peak, which occurred in the

374 thermal degradation range of cellulose, was more pronounced for paper wastes (CB, HP and PK)

375 and attributed to their higher cellulosic content when compared to those of yard wastes. The peak

376 observed in the pyrolysis stage can be mainly ascribed to the release of intra molecules of water

377 [9] from the hydroxyl group present in the structure of cellulose and to the release of hydroxyl

378 groups during the degradation of higher molecular weight molecules [38].

379 Under combustive conditions, the recurrent record of higher intensities of $\mathrm{H}_{2} \mathrm{O}^{+}$ions for $\mathrm{PP}$ and

380 PS indicated that the oxidation of HCs present in plastic is an important mechanistic feature. PP

381 displayed the highest intensity for the release of $\mathrm{H}_{2} \mathrm{O}$ during combustion which is consistent with

382 the high hydrogen content of PP (Table 1). The three MS peaks of $\mathrm{H}_{2} \mathrm{O}$ observed during the

383 combustion of PVC were found in good agreement with its DTG profile (Figure 2b). The release

384 of $\mathrm{H}_{2} \mathrm{O}$ during combustion of lignocellulosic-based materials (BR, LV, GR, CB, HP and PK)

385 occurred in two main steps. Similarly to pyrolysis, the release of water at low temperature could

386 correspond to dehydration. The second peak of $\mathrm{H}_{2} \mathrm{O}$ may be attributed to the degradation of 
387 glycosyl units present in cellulose [39] and most probably due to the oxidation of HC's released

388 in that temperature range $\left(200-500^{\circ} \mathrm{C}\right)$.

$389 \mathrm{CO}_{2} / \mathrm{CO}$ in gaseous products

390 During pyrolysis, the non-condensable, $\mathrm{CO}(\mathrm{m} / \mathrm{z} 28)$ and $\mathrm{CO}_{2}(\mathrm{~m} / \mathrm{z} 44)$, evolved over the whole 391 temperature range up to $600^{\circ} \mathrm{C}$ (Figures $6 \mathrm{~d}-\mathrm{h}$ ). Higher proportions of $\mathrm{CO}_{2}$ during the degradation 392 of lignocellulosic-materials (BR, LV, GR) were detected while more CO was released during the 393 degradation of cellulosic-based materials (CB, HP, PK). The formation of $\mathrm{CO}_{2}$ is believed to be a 394 consequence of the degradation of carbonyl $(\mathrm{C}=\mathrm{O})$ and carboxyl groups $(\mathrm{COOH})$ present in 395 hemicelluloses and cellulose and the product $\mathrm{CO}$ is the result of the scission of ether bonds (R-O396 R') [40] indicating that ether groups are more dominant in paper wastes than yard wastes. At

397 higher pyrolysis temperatures $\left(>600^{\circ} \mathrm{C}\right)$, peaks of $\mathrm{CO}$ and $\mathrm{CO}_{2}$ could be observed for paper 398 wastes suggesting self-gasification according to equation (4) [18] and also the decomposition of 399 calcium carbonates (equation (5)) present in paper wastes [41].

400 Stronger magnitude of both ions signal was observed for all the waste components burnt. Highest 401 peaks were exhibited by PP and PS at $340^{\circ} \mathrm{C}$ and $420^{\circ} \mathrm{C}$, respectively as the rich carbon content 402 of the plastics (Table 1) were oxidised to $\mathrm{CO}$ and $\mathrm{CO}_{2}$ in presence of air.

$$
\mathrm{C}+\mathrm{H}_{2} \mathrm{O} \rightarrow \mathrm{CO}+\mathrm{H}_{2}
$$

$$
\mathrm{CaCO}_{3} \rightarrow \mathrm{CaO}+\mathrm{CO}_{2}
$$

406 It is widely accepted that $\mathrm{H}_{2}$ is mainly produced from the cracking of $\mathrm{HCs}$ and their subsequent 407 degradation. Figure 6 revealed the presence of $\mathrm{H}_{2}$ from the pyrolytic degradation of all the nine 408 components. At higher temperatures $\left(600-1000^{\circ} \mathrm{C}\right)$, the concentration of $\mathrm{H}_{2}$ increased 409 considerably for PVC, yard and paper wastes during pyrolysis. Similar observations were made 
410 for $\mathrm{CO}(\mathrm{m} / \mathrm{z} 28)$ where $\mathrm{H}_{2}$ is being produced following equation (4). Secondary cracking of

411 higher molecular weight compounds and secondary pyrolysis of char residue contributed to the

412 release of $\mathrm{H}_{2}$ at elevated temperatures. The change in atmosphere from argon to air caused a high

413 decrease in the intensity of $\mathrm{H}_{2}{ }^{+}$ions, which could be attributed to the formation of water.

414 Compared to the signals of the other light gases $\left(\mathrm{CO}, \mathrm{CO}_{2}\right.$ and $\left.\mathrm{H}_{2} \mathrm{O}\right)$, the signal for $\mathrm{H}_{2}$ was

415 considered negligible in Figure 7.

$416 C_{x} H_{y}$ in gaseous products

417 The fragment ions of $\mathrm{m} / \mathrm{z} 16\left(\mathrm{CH}_{4}{ }^{+}\right)$and $\mathrm{m} / \mathrm{z} 26\left(\mathrm{C}_{2} \mathrm{H}_{2}{ }^{+}\right)$are mainly representative of the

418 evolution of HCs. The intensity of the fragments for $\mathrm{CH}_{4}$ was higher in most cases showing the

419 cracking and evolution of lighter molecular gases. A single narrow peak for both fragments

420 could be observed for PP and PS in the degradation stage at around $480^{\circ} \mathrm{C}$. Higher concentrations

421 in ions were observed in the second stage of devolatilization of PVC as HCs are formed after the

422 elimination of chlorine in the first stage and were subsequently degraded at higher temperatures

423 during the second stage. For cellulosic-based materials (BR, LV, GR, CB HP and PK), the first

424 peak shows the production of $\mathrm{CH}_{4}$ mainly comes from the cracking of methyl and methylene

425 groups present in hemicelluloses and cellulose and the second peak originates from the

426 degradation of lignin.

427 In the presence of oxygen, $\mathrm{HCs}$ were oxidised to $\mathrm{H}_{2} \mathrm{O}$ and $\mathrm{CO}_{2}$ causing a significant decrease in 428 the intensity of $\mathrm{m} / \mathrm{z} 16$ and m/z 26 (Figure 7). The intensity of $\mathrm{m} / \mathrm{z} 16$ was however higher than 429 expected and attributed to the amount of $\mathrm{O}_{2}$ in air.

$430 \mathrm{HCN} / \mathrm{NH}_{3}$ in gaseous products

431 The evolution of $\mathrm{m} / \mathrm{z} 16$ and $\mathrm{m} / \mathrm{z} 26$ are affected by the presence of $\mathrm{NH}_{3}$ and $\mathrm{HCN}$, respectively 432 [24]. However, volatile nitrogenous gaseous compounds such as $\mathrm{HCN}$ and $\mathrm{NH}_{3}$, are known to be 
433 present in significantly low concentrations in waste materials [42, 43]. The nitrogen content of

434 the different components in this study varied between 0 to $3 \%$ (Table 1), with plastic wastes

435 having negligible nitrogen content and GR having the highest. Giuntoli et al. [44] detected low

436 amounts of $\mathrm{NH}_{3}$ and $\mathrm{HCN}$ compared to the levels of other volatile species during the pyrolysis of

437 biomass residues. The gas analysis in another study [35] did not reveal the presence of $\mathrm{NH}_{3}$ and

$438 \mathrm{HCN}$. To conclude, the peaks at $\mathrm{m} / \mathrm{z} 16$ and $\mathrm{m} / \mathrm{z} 26$ could be associated to the simultaneous

439 release of $\mathrm{NH}_{3}$ and $\mathrm{HCN}$ and mainly $\mathrm{HCs}$ in the case of cellulosic-based components; thus

440 illustrating some limitations in the use of hard ionization source with mass spectrometry.

441 Higher intensity of signals attributed to $\mathrm{H}_{2}, \mathrm{CH}_{4}$ and $\mathrm{HCs}$ and lower intensity for $\mathrm{CO}, \mathrm{CO}_{2}$ and

$442 \quad \mathrm{H}_{2} \mathrm{O}$ signals collected under pyrolytic conditions suggest that the gas released could have a

443 higher specific energy than combustion gas.

\subsubsection{For the mixture of $P P, B R$ and $C B$}

445 For the sake of comparison, the MS peak areas were normalized to the initial mass of each 446 feedstock to better illustrate synergistic effect when mixing PP, BR and CB. Also, a calculated

447 MS peak area for the mixture, $\mathrm{MX}_{\mathrm{calc}}$, was determined by summing the relative contribution of 448 each single component (Table 4). The MS curve of the different fragments for MX under 449 pyrolytic and combustive conditions is given in Figure 8.

$450 \quad \mathrm{H}_{2} \mathrm{O}$ in gaseous product of the mixture

451 Water (m/z 18) evolution up to $200^{\circ} \mathrm{C}$ was observed during both degradation conditions and was 452 due to the free and physically bounded water in CB and BR. The relative area of the first peak 453 for both combustion and pyrolysis was $0.06 \mathrm{nsA} / \mathrm{mg}$ and was close to the relative area obtained 454 from $\mathrm{CB}(0.063 \mathrm{nsA} / \mathrm{mg})$ and $\mathrm{BR}(0.020 \mathrm{nsA} / \mathrm{mg})$. A second peak was observed at around $380^{\circ} \mathrm{C}$ 455 during pyrolytic degradation which corresponded mostly to the degradation of CB and BR. Both 
456 calculated and experimental normalized areas, 0.0320 and $0.0328 \mathrm{nsA} / \mathrm{mg}$ respectively, were

457 found close; thus suggesting that external water did not participate to further chemical reactions.

458 Peaks of $\mathrm{H}_{2} \mathrm{O}$ were absent during the second stage of degradation where mostly the

459 devolatilization of PP takes place.

460 With respect to the combustion of MX, a second peak at $370^{\circ} \mathrm{C}$ displayed an experimental

461 normalized area, $0.19 \mathrm{nsA} / \mathrm{mg}$, slightly higher than the calculated value, $0.15 \mathrm{nsA} / \mathrm{mg}$. In this

462 temperature range, positive deviations were observed (Figure 5) for the decomposition of MX

463 suggesting that synergistic effect should affect mainly secondary reactions such as the secondary

464 cracking of the char and oxidation of hydrocarbons. Hence a higher release of $\mathrm{H}_{2} \mathrm{O}$ fragments

465 was observed.

$466 \mathrm{CO}_{2} / \mathrm{CO}$ in gaseous products of the mixture

467 Under pyrolysis conditions, significant releases of $\mathrm{CO}$ and $\mathrm{CO}_{2}$ were observed at $375^{\circ} \mathrm{C}, 475^{\circ} \mathrm{C}$

468 and $700^{\circ} \mathrm{C}$. The highest peaks observed in the first stage were related to the degradation of BR

469 and CB (Figure 6). Deviations between first stage experimental and calculated normalized areas

470 (Table 4) confirmed that at this temperature $\left(375^{\circ}\right)$, the release of $\mathrm{CO}_{2}$ and $\mathrm{CO}$ was inhibited.

471 This result is in accordance to $\Delta \mathrm{W}$ (Figure 5) where negative deviations were observed in this

472 temperature range $\left(230-400^{\circ} \mathrm{C}\right)$. It corresponds to the start of the degradation of PP where due to

473 hydrogen transfer effects, the release of volatiles was slowed down. Similarly, for the second

474 peak $\left(475^{\circ} \mathrm{C}\right)$, lower peak areas were obtained (Table 4) which can be related to the negative

475 synergies observed at this temperature (Figure 5). The peak for the second stage corresponds to

476 the DTG peak of PP and the high release of hydrocarbons from the structure of PP prohibited the

477 release of $\mathrm{CO}$ and $\mathrm{CO}_{2}$ from lignocellulosic materials. Peaks observed at higher temperatures 
478 were similar to those obtained for CB and BR (Figure 6) showing self-gasification and

479 degradation of carbonates.

480 The intensity of the peaks was higher during combustion showing the oxidation of hydrocarbons

481 as compared to pyrolytic conditions. The experimental areas of the peaks were higher than the

482 contribution from each component in the sample and occurred at the temperature where high

483 positive deviations were obtained (Figure 5) showing that $\mathrm{CO}$ and $\mathrm{CO}_{2}$ were important products

484 during combustion resulting from synergistic reactions.

$485 \mathrm{H}_{2}$ in gaseous product of the mixture

486 The significant and gradual increase in $\mathrm{H}_{2}{ }^{+}$ions observed for MX pyrolysis could be related to

487 the cracking of heavy hydrocarbons also known as secondary reactions. An opposite trend was

488 observed during combustion where the concentration of $\mathrm{H}_{2}^{+}$ions decreased constantly.

$489 C_{x} H_{y}$ in gaseous product of the mixture

490 During pyrolysis of MX, 2 peaks were observed for m/z $16\left(\mathrm{CH}_{4}{ }^{+}\right)$and m/z $26\left(\mathrm{C}_{2} \mathrm{H}_{2}{ }^{+}\right)$at about

491380 and $500^{\circ} \mathrm{C}$. The normalized area of the first peak was lower than the calculated area

492 suggesting that the presence of PP inhibited the release of the volatile hydrocarbons from BR and

493 CB as also observed as a negative synergistic effect at this temperature (Figure 5). The second

494 peak displayed a larger area than expected (Table 4) confirming the high reactivity of PP's

495 intermediates at higher temperature promoting the thermal degradation of heavy non-volatiles

496 into $\mathrm{CH}_{4}$ and $\mathrm{C}_{2} \mathrm{H}_{2}$ ions. At this temperature, positive deviations were also observed (Figure 5)

497 which shows that the extent of devolatilization $(\Delta \mathrm{W})$ is in accordance to the MS peak areas.

498 It is worth noting that the release of ions during the combustion occurred in the same temperature

499 range, $250-415^{\circ} \mathrm{C}$, than pyrolysis. The experimental area value of $0.0099 \mathrm{nsA} / \mathrm{mg}$ appeared to be

500 higher than the calculated one, $0.0005 \mathrm{nsA} / \mathrm{mg}$ showing positive deviations. 
502 In order to gain qualitative insights into the synergistic effects occurring during the blending of

503 MSW components, the apparent activation energy $\left(\mathrm{E}_{\alpha}\right)$ for the overall and single stages of PP,

504 BR, CB and MX pyrolysis was determined and presented in Figure 9.

505 The $\mathrm{E}_{\alpha}$-dependency analysis for PP indicates that this latter remains quasi constant throughout

506 the entire pyrolysis and combustion, and therefore the single degradation stage (Figures 1 and 2)

507 can be associated to the single and averaged values of $\sim 250 \mathrm{~kJ} / \mathrm{mol}$ and $90 \mathrm{~kJ} / \mathrm{mol}$, respectively.

508 Although the thermal degradation of PP during pyrolysis mainly involves the breaking of the C-

509 C bonds whose energy bond is around $350 \mathrm{~kJ} / \mathrm{mol}$ [27], a lower $\mathrm{E}_{\alpha}$ was obtained for PP and can

510 therefore be attributed to the presence of weak link sites [45]. The slight variations from the

511 average value maybe related to the occurrence of various initiation mechanisms (e.g., breakage

512 of head to head linkages, fractionation of vinyldene-end groups) and random scission [46].

513 Under oxidative conditions, the lower $\mathrm{E}_{\alpha}$ values between $75-90 \mathrm{~kJ} / \mathrm{mol}$ for PP indicated that

514 oxygenated compounds may have favoured the thermal degradation pathways due to the

515 presence of hydroperoxide radicals according to Vyazovkin and Sbirrazzuoli [27].

516 As expected, pyrolysis and combustion of the biomass (BR) underwent through more complex

517 reactions mainly 2 main degradation stages. For BR pyrolysis, the initial average $\mathrm{E}_{\alpha}$ values, 160

$518 \mathrm{~kJ} / \mathrm{mol}$ (Figure $9 \mathrm{~b}$ ) were found similar to those reported for the degradation of hemicelluloses,

$519107-164 \mathrm{~kJ} / \mathrm{mol}$ [46]. An increase in $\mathrm{E}_{\alpha}$ values to $230 \mathrm{~kJ} / \mathrm{mol}$ could mark the beginning of

520 cellulose decomposition, which in general varies between 200 and $230 \mathrm{~kJ} / \mathrm{mol}$ [46]. In the case

521 of biomass combustion, these latter are usually associated to the devolatilization stage with

522 average $\mathrm{E}_{\alpha}$ values decreasing from $295 \mathrm{~kJ} / \mathrm{mol}$ to $95 \mathrm{~kJ} / \mathrm{mol}$ and to the char oxidation stage with a

523 practically average value of around $150 \mathrm{~kJ} / \mathrm{mol}$. When considering the respective $\mathrm{E}_{\alpha}$-dependency 
524 determined for each stage, the start of $2^{\text {nd }}$ combustion stage requires less energy than the $1^{\text {st }}$

525 combustion stage. $E_{\alpha}$ during pyrolysis were higher than combustion showing a different

526 degradation mechanism occurring in air with reactions of lower activation energy.

527 The $\mathrm{E}_{\alpha}$ during the initial degradation stage of cellulosic derived feedstock (CB) was lower than 528 that ascribed to the biomass-derived feedstock (BR) with average values of $\sim 65 \mathrm{~kJ} / \mathrm{mol}$ during

529 both pyrolysis and combustion. During pyrolysis of $\mathrm{CB}$, an averaged $\mathrm{E}_{\alpha}$ value of $200 \mathrm{~kJ} / \mathrm{mol}$ was

530 obtained which corresponded to those of cellulose degradation [46]. The almost constant $\mathrm{E}_{\alpha}$

531 values (Figure 9c) confirmed the uniform energetic demand of cellulose degradation reactions.

532 For combustion, lower $\mathrm{E}_{\alpha}$ of around $170 \mathrm{~kJ} / \mathrm{mol}$ were obtained in the first stage of degradation as

533 compared to $\mathrm{E}_{\alpha}$ of around $200 \mathrm{~kJ} / \mathrm{mol}$ in the second stage. Similar to BR, $\mathrm{E}_{\alpha}$ were lower during

534 combustion when compared to pyrolysis. The degradation of cellulose in air might therefore be

535 enhanced by molecular oxygens through radical interactions.

536 When the mixture was respectively exposed to inert and oxidative atmospheres (Figure 9d),

537 comparable key features in $\mathrm{E}_{\alpha}$-dependency were observed: both processes occurred in 2 main

538 stages with higher average $\mathrm{E}_{\alpha}$ values for pyrolysis. However, slight deviations in $\mathrm{E}_{\alpha}$ values from

539 those obtained for the single feedstocks were found. For example, the $\mathrm{E}_{\alpha}$ values and the

540 noticeable decreasing trend of the $\mathrm{E}_{\alpha}$ curve for the $1^{\text {st }}$ degradation stage when $\alpha$ is increased is

541 almost equivalent to $\mathrm{E}_{\alpha}$-dependencies obtained for $\mathrm{CB}$ and $\mathrm{BR}$. This result suggests that

542 mechanisms involved during $1^{\text {st }}$ stage of MX pyrolysis are equivalent to those of cellulose-

543 derived feedstocks and can explain the absence of synergies mentioned in section 3.1.3. The

544 second stage of degradation of MX is mainly dominated by the degradation of PP. The $\mathrm{E}_{\alpha}$ values

545 for the $2^{\text {nd }}$ stage were higher than those for PP, BR and CB up to $\alpha=0.65$ during pyrolysis (Figure

546 9d) thus indicating that intermediate species involved have a greater thermal stability. This 
547 greater amount of energy required of around $300 \mathrm{~kJ} / \mathrm{mol}$ instead of $250 \mathrm{~kJ} / \mathrm{mol}$, corresponds to

548 the negative synergistic effects described earlier in the section 3.1.3 and is attributed to PP

549 degradation. However, this energy penalty is compensated by the lowest energetic requirements

550 for $\alpha>0.7$ reaching $160 \mathrm{~kJ} / \mathrm{mol}$ at $\alpha=0.9$. These lower E $\alpha$ values suggest that further

551 degradations of PP eased the overall degradation mechanisms, which is in accordance with the

552 positive synergistic effects described earlier in section 3.12. This lower activation energy and

553 positive deviations were observed until the end of the second degradation stage. In the case of

554 combustion, this positive impact of PP addition was even more significant with noticeable lowest

$555 \quad E_{\alpha}$ values for both degradation stages (Figure 9d), which was also corroborated by the extent of

556 positive synergy effects (Table 4). Less energy is required during the combustion of MX as

557 compared to the single components. Positive synergistic effects are indeed present during

558 combustion of MX where the degradation mechanism occurs through a lower activation energy

559 pathway. Similar to the single components, lower $\mathrm{E}_{\alpha}$ was observed during combustion as

560 compared to pyrolysis and hence indicating that the presence of oxygen indeed changes the

561 degradation pathway with reaction of lower energies occurring.

\section{Conclusions}

563 Real time pyrolysis and combustion characteristics (i.e., solid conversion and release of

564 volatiles) of nine components representative of current waste streams found in Mauritius and

565 their mixture were investigated using a thermogravimetric analyser coupled to a mass

566 spectrometer (TGA-MS). The mixture of MSW composed of lignocellulosic and plastic-based

567 materials was degraded in two main stages under pyrolysis conditions while the combustion of

568 the same mixture occurred in one main stage. Considering the differences between experimental

569 and calculated results, it was found that both negative and positive synergistic effects were 
570 present at different stages during pyrolysis. Negative synergistic effects observed in the $1^{\text {st }}$ stage

571 of pyrolysis between $330-550^{\circ} \mathrm{C}$ associated with higher $\mathrm{E}_{\alpha}$. resulted in the formation of solid

572 residue delaying the degradation of lignocellulosic materials. In this stage, the expected areas for

573 the release of $\mathrm{CH}_{4}, \mathrm{CO}$ and $\mathrm{CO}_{2}$ were lower than experimental areas obtained showing that the

574 release of the volatiles were slowed down. Above $500^{\circ} \mathrm{C}$, increasing weight losses indicated that

575 the decomposition of solid residues was favoured due to the presence of heterogeneous reactions

576 of lower $\mathrm{E}_{\alpha}$ between the char and reactive volatiles evolved from the degradation of PP. The

577 difference between the value of the expected and experimental peak areas for the different

578 volatiles tracked also confirmed the presence of positive synergies in this stage. Under oxidative

579 atmosphere, only positive deviations up to $14 \%$ were recorded between $260-500^{\circ} \mathrm{C}$; thus

580 indicating that homogeneous interactions between volatiles enhanced the combustion of the

581 mixture associated with lower $\mathrm{E}_{\alpha}$. This study confirms that the adopted experimental

582 methodology based on TGA-MS is suitable for revealing the extent of synergistic reactions

583 during co-pyrolysis and co-combustion.

584 Acknowledgement

585 We gratefully acknowledge Mauritius research council (MRC), University of Stellenbosch

586 (International Office) and PAFROID program for financial support. 
[1] P.Modak, Community-based Waste Management and Composting for Climate/Cobenefits, Case of Bangladesh, The International Consultative Meeting on expanding Waste Management Services in Developing Countries, 18-19 March, Tokyo, Japan (2010).

[2] P. Gopee, M.D. Nowbuth, Y.B. Moonshiram, Evaluating the potential for recycling of solid waste in Mauritius, $1^{\text {st }}$ Internaltional Exergy, Life cycle assessment and sustainability workshop and symposium proceedings, 4-6 June, Wisyros-Greece, (2009), pp472-479

[3] A.M. Troschinetz, J.R. Mihelcic, Sustainable recycling of municipal solid waste in developing countries, Waste Management 29 (2009) 915-923.

[4] R. Mohee, S. Rungasamy, M.A.Z, Bundhoo, Solid Waste Management in Mauritius, with emphasis on the National Composting Plant, Journal of Institution of Engineers Mauritius (2012) 67-73 decomposition of MSW in N2,CO2 and CO2/N2atmospheres, Fuel Process. Technol. 102 (2012) 18-23.

[6] A. Bosman, I. Vandereydt, D. Geysen, L. Helsen, The crucial role of Waste-to-Energy technologies in enhanced landfill mining: a technology review, Journal of Cleaner Production (2012) 1-14

[7] R. Mohee, Assessing the recovery potential of solid waste in Mauritius, Resources, Conservation and Recycling, 36 (2002) 33-43. 
610 [8] I. Velghe, R. Carleer, J. Yperman, S.Schmeurs, Study of the pyrolysis of municipal solid $611 \quad$ waste, J. Anal. Appl. Pyrolysis 92 (2011) 366-375

612 [9] T. Karayildirim, J. Yanik, M. Yuksel, Y. Bochorn, Characterisation of products from 613 pyrolysis of waste sludges, Fuel 85 (2006) 1498-1508.

614 [10] A. Skreiberg, O. Skreiberg, J. Sandquist, L. Sorum, TGA and macro-TGA 615 characterisation of biomass fuels and fuel mixture, Fuel 90 (2011) 2182-2197.

616 [11] N. Tudorachi, A.P. Chiriac, TGA/FTIR/MS study on thermal decomposition of 617 poly(succinimide) and sodium poly(aspartate), Polym. Test. 30 (2011) 397-407. 618 [12] S. Singh, C. Wu, T. Williams, Pyrolysis of waste materials using TGA-MS and 619 TGA-FTIR as complementary characterisation techniques, J. Anal. Appl. Pyrolysis 94 $620 \quad$ (2012) 99-107.

621 [13] J. Heinkkinnen, J. Hordijk, W. Jong, H, Spliethoff, Thermogravimetry as a tool to 622 classify waste components to be used for energy production, J. Anal. Appl. Pyrolysis 71 $623 \quad$ (2004) 883-900.

624 [14] M. Muthuraman, T. Namioka, K. Yoshikawa, A comparative study on co-combustion 625 performance of municipal solid waste and Indonesian coal with high ash Indian coal: A 626 thermogravimetric analysis, Fuel Process. Technol. 91 (2010) 550-558.

627 [15] Z. Lai, X. Na. Y. Tang, H. Lin, A study on municipal solid waste combustion in $\mathrm{N}_{2} / \mathrm{O}_{2}$ 628 and $\mathrm{CO}_{2} / \mathrm{O}_{2}$ atmosphere from perspective of TGA, Energy 36 (2011) 819-824.

629 [16] G. Skrodas, P. Grammelis, P. Basinas, M. Prokopidou, E. Kakaras, G.P.

630 Sakellaropoulos, A thermochemical conversion study on the combustion of residue 631 derived fuel, Water air soil pollution 9(2009) 151-157 
632 [17] C.J. Gomez, E. Meszaros, E. Jakab, E. Velo, L. Puigjaner, Thermogravimetry/mass

633 spectrometry study of woody residues and an herbaceous biomass crop using PCA

634 techniques, J. Anal. Appl. Pyrolysis 80 (2005) 416-426.

635 [18] Y.F. Huang, W.H. Kuan, P.T. Chiwh, S.L. Lo, Pyrolysis of biomass by thermal analysis

$636-$ mass spectrometry, Bioresource technology volume 102 (2011) 3527-3534.

637 [19] L. Tiikma, I. Johannes, H. Luik, A. Gregor, Synergy in the hydrothermal pyrolysis of oil 638 shale/sawdust blends, J. Anal. Appl. Pyrolysis 117 (2016) 247-256.

639 [20] L. Zhou, Y. Wang, Q. Huang, J. Cai, Thermogravimetric characteristics and kinetics of $640 \quad$ plastic and biomass blends co-pyrolysis, Fuel Process. Technol. 87 (2006) 963-969.

641 [21] G. Wang, A. Li, Thermal decomposition and kinetics of mixtures of polylactic acid and 642 biomass during co-pyrolysis, Chinese J. Chem, Eng. 16 (2008) 929-933.

643 [22] Z.Wu, S.Wang, J.Zhao, L.Chen, H.Meng, Synergistic effect on thermal behaviour 644 during co-pyrolysis of lignocellulosic biomass model components blend with bituminous 645 coal, Bioresource technology 169 (2014) 220-228.

646 [23] M.J. Antal, G. Varhegyi, Cellulose pyrolysis kinetics: the current state of knowledge, 647 Industrial \& Engineering, Chemistry Research 34 (1995) 703-717.

648 [24] NIST, 2013. NIST chemistry webBook. US secretary of commerce. Available from $649 \quad$ http://webbook.nist.gov/chemistry/

650 [25] S. Vyazovkin, A.K. Burnham, J.M. Criado, L.A. Perez-Maqueda, C. Popescu, N. 651 Sbirrazzuoli, ICTAC Kinetics Committee recommendations for performing kinetic 652 computations on thermal analysis data, Thermochimica Acta, 520 (2011) 1-19. 
[26] A.O. Aboyade, T.J. Hugo, M. Carrier, E.L. Meyer, R. Stahl., J.H. Knoetze, J.F.

654 Görgens, Non-isothermal kinetic analysis of the devolatilization of corn cobs and sugar

$655 \quad$ cane bagasse in inert atmosphere, Thermochim. Acta 517 (2011) 81-89.

656 [27] S. Vyazovkin, N. Sbirrazzuoli, Isoconversional kinetic analysis of thermally stimulated processes in polymers, Macromol. Rapid. Commun.27 (2006) 1515-1532

658 [28] J. Blazevsca-Gilez, D. Spaseska, Formal kinetic analysis of PVC thermal degradation, 659 Journal of the University of Chemical Technology and Metallurgy, 45(3) (2010), 251660254.

661 [29] H. Bockhorn, J. Hentschel, A. Hornung, U. Hornung, Environmental engineering: stepwise pyrolysis of plastic waste, Chem Eng Sci 54 (1999) 3043-3051.

663 [30] V.S. Loo, J. Koppejan, Handbook of biomass combustion and co-firing, UK, Earthscan (2002)

665 [31] P.R. Diaz, Z.H. Shemet, V.A. Lavrenko, V.A. Khristich, Studies on thermal decomposition and combustion mechanism of bagasse under non-isothermal conditions, Thermochim. Acta 93 (1985)349-352.

668 [32] G. Varhegyi, M.J. Antal, T. Szekely, P. Szabo, Kinetics of the thermal decomposition 669 of cellulose, hemicellulose, and sugarcane bagasse, Energy\&Fuels 3 (1989) 329-335.

670 [33] M. Brebu, C. Vasile, Thermal degradation of lignin - A review, Cellulose Chemistry and Technology 44 (9) (2010) 353-363.

672 [34] A.G. Barneto, J.J.A. CarmonaJ, E. Martin, J.D. Blanco, Kinetic models based in 673 biomass components for the combustion and pyrolysis of sewage sludge and its compost, $674 \quad$ J. Anal. Appl. Pyrolysis 86 (1) (2009) 108-114. 
675 [35] W.K. Buah, A.M. Cunlife, P.T. Williams, Characterisation of products from the

676 pyrolysis of municipal solid wastes, Process safety and Environmental 85 (2007) 450-

$677 \quad 457$.

678 [36] A. Dermidas, Pyrolysis mechanisms of biomass materials, Energy source part A 31 (2009)

$679 \quad 1186-1193$.

680 [37] M. Ahmaruzzaman, D.K. Sharma, Co-processing of petroleum vacuum residue with $681 \quad$ plastics, coal and biomass and its synergistic effects, Energy \& Fuels 21 (2) (2007) 891$682 \quad 899$.

683 [38] J. Adam, M. Blazso, E. Meszaros, M. Stocker, M.H. Nilsen, A. Bouzga, J.E. Hustad, M. 684 Gronli, G. Oye, Pyrolysis of biomass in the presence of A1-MCM-41 catalysts, Fuel 84 $685 \quad$ (2005) 1494-1502.

686 [39] D. Lopez-Gonzalez, M. Fernandez-Lopez, J.L. Valverde, L. Sanchez-Silva, 687 Thermogravimetric-mass spectrometric analysis on combustion of lignocellulosic $688 \quad$ biomass, Bioresource Technology 143(2013) 562-574.

689 [40] K. Cheng, W.T. Winter, A.J. Stipanovic, A modulated-TGA approach to the kinetics of 690 lignocellulosic biomass pyrolysis/combustion. Polym. Degrad. Stab. 97(9) (2012) 1606$691 \quad 1615$.

692 [41] .A.J. Ridout, M. Carrier, J. Gorgens, Fast pyrolysis of low and high ash paper waste 693 sludge: Influence of reactor temperature and pellet size, J. Anal. Appl. Pyrolysis 111 $694 \quad$ (2015) 64-75.

695 [42] J.H. Ferasse, S. Chavez, P. Arlabosse, N. Dupuv, Chemometrics as a tool for analysis of 696 evolved gas during the thermal treatment of sewage sludge using coupled TG-FTIR, 697 Thermochim. Acta 404 (2003) 97-108. 
[43] L. Tao, G. Zhao, J. Qian, Y. Qin, TG-FTIR characterisation of pyrolysis of waste mixtures of paint and tar slag, J. Hazard. Mater. 175 (2010) 754-761.

[44] J. Giuntoli, W. Jong, S. Arvelakis, H. Spliethoff, A.H.M. Verkooijen, Quantitative and Kinetic TG-FTIR study of biomass residue pyrolysis: dry distiller's grain with soluble (DDGS) and chicken manure, J. Anal. Appl. Pyrolysis 85 (2009) 301-312.

[45] J.D. Peterson, S. Vyazovkin, C.A. Wight, Kinetics of the thermal and thermo-oxidative degradation of polystyrene, polyethylene and polypropylene, Macromol.Chem.Phys., 202 (2001) 775-784.

[46] P. Grammelis, P. Basinas, A. Malliopoulou, G. Sakellaropoulos, Pyrolysis kinetics and combustion characteristics of waste recovered fuels, Fuel 88 (2009) 195-205.

\section{Table 1}

Standard fuel analysis

\begin{tabular}{lllllllllll}
\hline Sample & \multicolumn{3}{c}{ Proximate Analysis (wt\% db) } & \multicolumn{1}{c}{ Ultimate Analysis (wt\% db) } & \multicolumn{2}{c}{$\begin{array}{l}\text { HHV } \\
(\mathrm{MJ} / \mathrm{kg})\end{array}$} \\
\cline { 2 - 12 } & MC & VM & FC & Ash & C & H & $\mathrm{O}^{\mathrm{a}}$ & $\mathrm{N}$ & $\mathrm{S}$ & \\
\hline PVC & 0.02 & 88.95 & 8.67 & 2.36 & 38.8 & 5.14 & 53.61 & 0.09 & - & n.d \\
& & & & & & & $\mathrm{b}$ & & & \\
PP & 0.00 & 99.85 & 0.00 & 0.15 & 85.03 & 14.8 & 0.00 & 0.00 & 0.00 & 42.80 \\
PS & 0.50 & 99.24 & 0.02 & 0.24 & 90.55 & 7.82 & 0.00 & 0.17 & 1.22 & 38.60
\end{tabular}




\begin{tabular}{lllllllllll} 
BR & 0.71 & 79.80 & 17.27 & 2.22 & 45.35 & 5.96 & 44.55 & 0.22 & 1.70 & 21.43 \\
LV & 1.68 & 72.53 & 20.76 & 5.03 & 46.13 & 6.15 & 42.13 & 0.56 & 0.10 & 17.66 \\
GR & 1.77 & 61.27 & 14.86 & 22.10 & 32.65 & 4.95 & 35.24 & 3.07 & 1.99 & 20.64 \\
CB & 3.24 & 78.07 & 8.64 & 10.05 & 40.64 & 6.19 & 42.97 & 0.05 & 0.10 & 20.46 \\
PK & 3.40 & 78.38 & 7.43 & 11.79 & 42.6 & 6.41 & 37.08 & 0.21 & 1.91 & 22.75 \\
HP & 3.20 & 83.55 & 10.04 & 3.21 & 39.6 & 5.74 & 49.40 & 0.20 & 1.85 & 15.30 \\
\hline
\end{tabular}

719 db- Dry Basis MC-Moisture content VM- Volatile matter FC-Fixed Carbon HHV- Higher Heating Value

720

$721 \quad$ Bay difference

$722 \quad{ }_{\text {It is } \mathrm{Cl} \text { for PVC }}$

723

724 
Table 2

726 Characteristics of the TGA experiments of single components under pyrolytic conditions 727

\begin{tabular}{llllll}
\hline Sample & $\begin{array}{l}\text { Solid } \\
\text { Residue } \\
\text { at } 1000^{\circ} \mathrm{C}\end{array}$ & $\begin{array}{l}\text { DTG } \\
\text { temperature }\left({ }^{\circ} \mathrm{C}\right)\end{array}$ & $\begin{array}{l}\text { DTG max } \\
(1 / \mathrm{s})\end{array}$ & $\begin{array}{l}\text { Tonset } \\
\left({ }^{\circ} \mathrm{C}\right)\end{array}$ & $\begin{array}{l}\text { Temperature } \\
\text { Range }\left({ }^{\circ} \mathrm{C}\right)\end{array}$ \\
& 11.5 & $327,495^{\mathrm{a}}$ & -0.0032, & -296 & $240-400,400-560$ \\
\hline PVC & & $0.0013^{\mathrm{a}}$ & & \\
& & & -0.0099 & 454 & $370-500$ \\
PP & 2.8 & 479 & -0.0099 & 409 & $330-475$ \\
PS & 2.9 & 425 & -0.0025 & 320 & $201-500$ \\
BR & 18.7 & 375 & -0.0015 & 299 & $150-520$ \\
LV & 23.8 & 368 & -0.0019 & 274 & $160-600$ \\
GR & 25.5 & 330 & -0.0030, & -328 & $230-410$, \\
PK & 15.5 & $362,486,700^{\mathrm{a}}$ & 0.0017, & - & $540,540-720$ \\
& & & $0.0003^{\mathrm{a}}$ & & \\
& & & -0.0039 & 333 & $230-600$ \\
CB & 16.7 & 370 & -0.0051 & 334 & $210-560$ \\
HP & 10.7 & 375 & $-0.02,-0.03$ & 327 & $200-415,415-525$ \\
MX & 9.84 & 375,481 & &
\end{tabular}

$728 \quad$ a Several distinct peaks observed

729

730

731

732

733

734

735

736

737

738

739

740

741

742

743

744

745

746

747

748

749 


\section{Table 3}

Characteristics of the TGA experiments of single components under combustion conditions

\begin{tabular}{|c|c|c|c|c|c|c|c|}
\hline Sample & $\begin{array}{l}\text { Solid residue } \\
\text { at } 1000^{\circ} \mathrm{C} \\
(\%)\end{array}$ & $\begin{array}{l}\text { DTG peak } \\
\text { temperature }\left({ }^{\circ} \mathrm{C}\right)\end{array}$ & $\begin{array}{l}\text { DTG max } \\
(1 / s)\end{array}$ & & $\begin{array}{l}\text { Tonset } \\
\left({ }^{\circ} \mathrm{C}\right)\end{array}$ & $\begin{array}{l}\text { Temperature } \\
\text { Range }\left({ }^{\circ} \mathrm{C}\right)\end{array}$ & \\
\hline PVC & 0.14 & $309,450^{\mathrm{a}}$ & $\begin{array}{l}-0.0045 \\
0.0115^{\mathrm{a}}\end{array}$ & - & 295 & $\begin{array}{l}225-375, \\
500,500-690^{a}\end{array}$ & $\begin{array}{l}430- \\
a\end{array}$ \\
\hline PP & 1.19 & 380 & -0.0058 & & 348 & $260-400$ & \\
\hline PS & 1.21 & 400 & -0.0080 & & 380 & $275-425$ & \\
\hline BR & 1.67 & $335,460^{\mathrm{a}}$ & $\begin{array}{l}-0.0039 \\
0.0007^{\mathrm{a}}\end{array}$ & - & 311 & $\begin{array}{l}200-370, \\
520^{\mathrm{a}}\end{array}$ & $370-$ \\
\hline LV & 4.00 & $230,430^{\mathrm{a}}$ & $\begin{array}{l}-0.0021, \\
0.0014^{\mathrm{a}}\end{array}$ & - & 291 & $\begin{array}{l}190-370, \\
550^{\mathrm{a}}\end{array}$ & $370-$ \\
\hline GR & 9.85 & $295,435^{\mathrm{a}}$ & $\begin{array}{l}-0.0017, \\
0.0014^{\mathrm{a}}\end{array}$ & - & 257 & $\begin{array}{l}125-360, \\
545^{\mathrm{a}}\end{array}$ & $360-$ \\
\hline PK & 8.78 & $335,425,690^{\mathrm{a}}$ & $\begin{array}{l}-0.0043, \\
0.0010 \\
0.0028^{\mathrm{a}}\end{array}$ & - & 312 & $\begin{array}{l}280-380, \\
490,500-715\end{array}$ & $385-$ \\
\hline $\mathrm{CB}$ & 10.30 & $340,420^{\mathrm{a}}$ & $\begin{array}{l}-0.0063 \\
0.0013^{\mathrm{a}}\end{array}$ & - & 327 & $\begin{array}{l}210-375, \\
480^{\mathrm{a}}\end{array}$ & $375-$ \\
\hline HP & 0.53 & $345,435^{\mathrm{a}}$ & $\begin{array}{l}-0.0087 \\
0.0036^{\mathrm{a}}\end{array}$ & - & 328 & $\begin{array}{l}260-385, \\
500^{\mathrm{a}}\end{array}$ & $385-$ \\
\hline MX & 3.45 & $348,425^{\mathrm{a}}$ & $-0.04,-0.001$ & & 311 & $225-400,400$ & -470 \\
\hline
\end{tabular}


Table 4

775 Relative areas of MS peaks for MX and pure components

\begin{tabular}{|c|c|c|c|c|c|c|c|c|c|c|c|c|c|c|}
\hline \multirow{4}{*}{$\mathrm{m} / \mathrm{z}$} & \multicolumn{9}{|c|}{ Pyrolysis } & \multicolumn{5}{|c|}{ Combustion } \\
\hline & & & & & \multicolumn{5}{|c|}{ Degradation Stages } & & & & & \\
\hline & & Stage 1 & $\mathrm{nsA} / \mathrm{mg}$ ) & & & & ge 2 (nsA & $\mathrm{mg})$ & & \multicolumn{5}{|c|}{ Stage $1(\mathrm{nsA} / \mathrm{mg})$} \\
\hline & $\begin{array}{c}\text { BR } \\
0.0003\end{array}$ & $\begin{array}{c}\mathrm{CB} \\
0.0017\end{array}$ & $\begin{array}{c}\mathrm{MX}_{\text {calc }} \\
0.0020\end{array}$ & $\begin{array}{c}\mathrm{MX}_{\exp } \\
0.0010\end{array}$ & $\begin{array}{r}\text { BR } \\
-\end{array}$ & CB & $\begin{array}{c}\mathrm{PP} \\
0.0013\end{array}$ & $\begin{array}{c}\mathrm{MX}_{\text {calc }} \\
0.0013\end{array}$ & $\begin{array}{c}\mathrm{MX}_{\mathrm{exp}} \\
0.0047\end{array}$ & $\begin{array}{c}\text { BR } \\
0.0030\end{array}$ & $\begin{array}{c}\text { CB } \\
0.0013\end{array}$ & $\begin{array}{c}\mathrm{PP} \\
0.0030\end{array}$ & $\begin{array}{l}\mathrm{MX}_{\text {calc }} \\
0.0073\end{array}$ & $\begin{array}{c}\mathrm{MX}_{\exp } \\
0.0096\end{array}$ \\
\hline 18 & 0.0150 & 0.0170 & 0.0320 & 0.0328 & - & - & - & & - & 0.0430 & 0.0270 & 0.0800 & 0.1500 & 0.1900 \\
\hline 26 & 0.0003 & 0.0013 & 0.0016 & 0.0006 & 0.0001 & - & 0.0051 & 0.0052 & 0.0073 & 0.0002 & 0.0003 & 0.0027 & 0.0032 & 0.0039 \\
\hline 28 & 0.0057 & 0.0122 & 0.0179 & 0.0153 & 0.0023 & 0.0008 & - & 0.0031 & 0.0026 & 0.0640 & 0.0770 & 0.0910 & 0.2320 & 0.2340 \\
\hline 44 & 0.0107 & 0.0117 & 0.0224 & 0.0196 & 0.0014 & - & - & 0.0014 & 0.0007 & 0.0550 & 0.0610 & 0.0740 & 0.1900 & 0.2100 \\
\hline
\end{tabular}

776 


\section{a) 100}

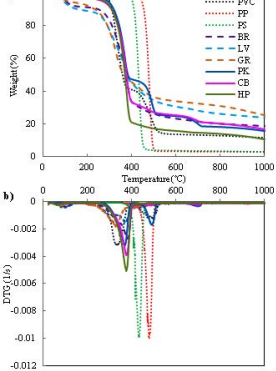




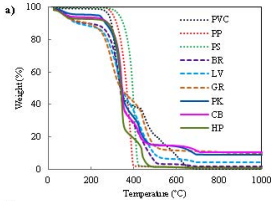

b)

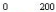

400

600

ख्व

100

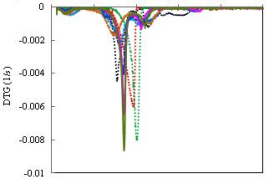




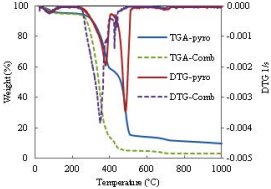


a)

Tempatus $(\mathrm{C})$
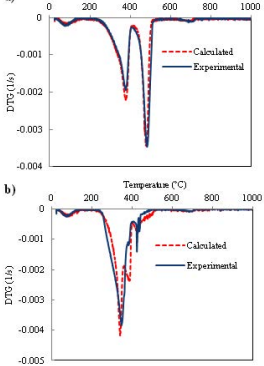


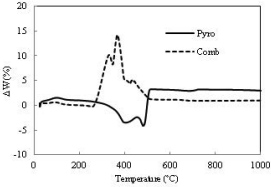



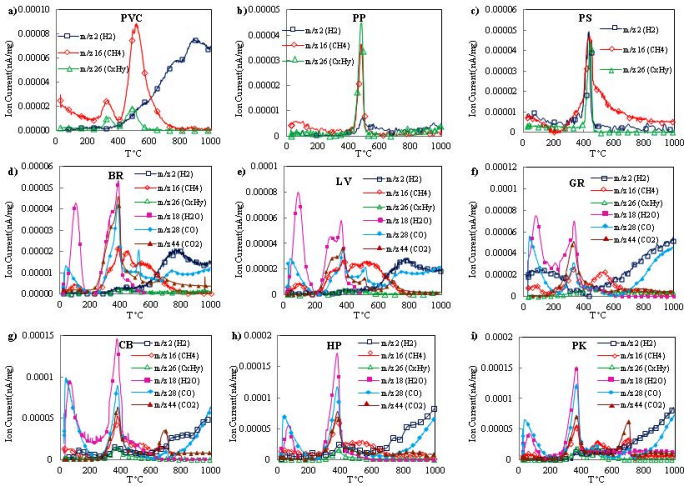

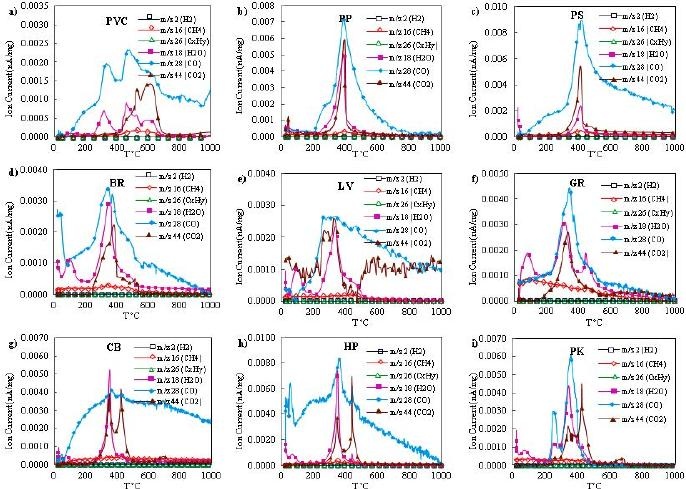

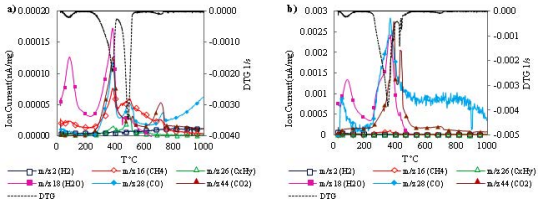

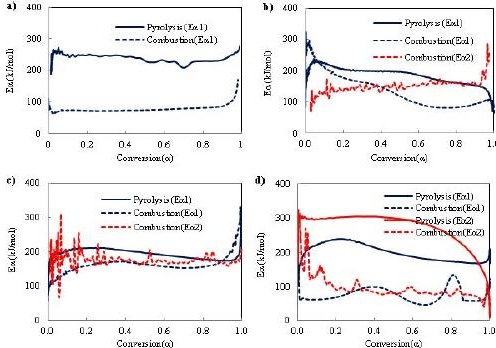